\title{
AVALIAÇÃO DO RENDIMENTO DO DESTILADOR SOLAR NO TRATAMENTO DO LIXIVIADO DE ATERRO SANITÁRIO DO MUNICÍPIO DE SETE LAGOAS
}

Isadora Ferreira dos Santos - isadora.3110@ hotmail.com

Centro Universitário de Sete Lagoas - Unifemm

Fernando Augusto Moreira - fam.quimico@ gmail.com

Centro Universitário de Sete Lagoas - Unifemm

Josiane Tamar de Oliveira - josianetamardeoliveira@yahoo.com.br

Centro Universitário de Sete Lagoas - Unifemm

Marley Beatriz Assis Lima - marleybeatriz@ gmail.com

Escola Técnica Municipal de Sete Lagoas - ETMSL 


\section{RESUMO}

O grande avanço da tecnologia e o rápido crescimento das cidades, vem ocasionando sérios problemas ao meio ambiente. Um dos problemas que mais têm causado preocupação são a grande quantidade de resíduos sólidos que essas grandes metrópoles geram. No Brasil, a técnica mais utilizada para a disposição final destes resíduos é o aterro sanitário. Contudo, um dos problemas relacionados aos aterros, está associado à degradação dos resíduos aterrados, ocasionando a formação do lixiviado de aterro sanitário, também conhecido como chorume. O lixiviado de aterro sanitário é um líquido escuro, ácido e de elevada DQO proveniente da decomposição da matéria orgânica presente nos resíduos depositados nos aterros sanitários. Por ser altamente poluidor esse efluente necessita de tratamentos específicos para minimizar os impactos causados pelo mesmo. Portanto, esse trabalho tem por objetivo avaliar o rendimento do destilador solar como tecnologia de tratamento de lixiviado de aterro sanitário, bem como avaliar a viabilidade técnica de aplicar o destilador solar em escala real para o aterro sanitário de Sete Lagoas. Análises físico-químicas foram realizadas para avaliar a eficiência do sistema, sendo determinado também a taxa de aplicação superficial e a área requerida para implantação da tecnologia no aterro de Sete Lagoas. A partir dos dados levantados neste estudo, conclui-se que o processo de destilação solar configurase como uma alternativa tecnicamente viável para o tratamento do lixiviado em questão, possibilitando uma redução significativa dos seus contaminantes, com redução de $98 \%$ em massa do total de lixiviado gerado e eficiência de $97 \%$ de remoção de DQO. A análise de rendimento do destilador solar indica que não é viável a implantação do modelo testado em escala real, uma vez que um eventual uso deste equipamento implica em uma demanda de área cerca de 3,9 vezes maior do que a área do sistema de tratamento atual.

\section{INTRODUÇÃO/ OBJETIVO}

Sete Lagoas é um município considerado polo industrial, localizado a aproximadamente 72 quilômetros de Belo Horizonte, que segundo o IBGE possuía em julho de 2015 uma população estimada de 232.107 habitantes. A geração de resíduos sólidos de Sete Lagoas chega a 140 toneladas por dia, sendo realizada coleta convencional na área central diariamente e, nos bairros, três vezes por semana, atendendo também a zona rural, porém com uma frequência reduzida, uma vez a cada sete dias. (PREFEITURA DE SETE LAGOAS, 2014) 
A destinação destes resíduos é feita no aterro Sanitário de Sete Lagoas, inaugurado em 2009, em substituição do até então aterro controlado que havia no município, tendo área de 11 mil metros quadrados e dimensionado para operar durante. (PREFEITURA DE SETE LAGOAS, 2014), sendo a formação do lixiviado no interior do aterro sanitário se dá através das reações físico-químicas que atuam na solubilização dos resíduos e a fermentação que produz os ácidos orgânicos (BASTOS, 2011)

Por se tratar de um efluente muito complexo e heterogêneo com grandes quantidades de matéria orgânica (biodegradável e também refratária), um tratamento adequado é difícil de ser estabelecido. Bacelar (2010) relata que diversas técnicas podem ser empregadas para o tratamento do lixiviado dentro do aterro sanitário, devendo ser baseadas na remoção de DQO e DBO como principais pré-requisitos para o lançamento em um corpo d'água natural.

O tratamento biológico por lagoas de estabilização é a principal tecnologia utilizada para tratamento de lixiviado por ser mais acessível, porém existem inúmeros desvantagens sobre o seu uso, por exemplo: grande disponibilidade de áreas para implantação, possibilidade de maus odores, necessidade de remoção periódica do lodo da lagoa sem contar na dificuldade em atender aos padrões exigidos pela legislação para o lançamento em curso d'água.

Uma tecnologia de baixo custo operacional com potencial para aplicação do tratamento de lixiviado de aterro sanitário é a destilação solar. De acordo com Sousa (2010), o tratamento consiste em um processo térmico que utiliza a energia solar de forma direta para promover o aquecimento e mudança de fase do líquido com posterior condensação, reproduzindo o ciclo natural da água, o que permite a remoção de contaminantes.

Sá (2008) em seu trabalho sobre a evaporação natural do lixiviado através de um destilador solar destaca o caracter promissor da destilação solar destacando a necessidade de e pesquisas com vistas a melhorar os rendimentos e aumentar a aplicabilidade dessa técnica. Neste contexto, o presente estudo tem por objetivo estudar a viabilidade técnica de implantação do destilador solar para tratamento de lixiviado do aterro de Sete Lagoas, estando focado na análise da eficiência e no potencial de implantação em escala real. 


\section{METODOLOGIA}

Para avaliação do destilador solar foi realizado estudo em escala de laboratório no campus do Centro Universitário de Sete Lagoas (UNIFEMM), no período de junho a outubro de 2015, consistindo nas etapas descritas a seguir:

\subsection{Características do equipamento}

O destilador foi construído no formato piramidal, tendo as dimensões definidas em função da metodologia proposta por Jucá et al (2009), sendo estas: caixa de base: 0,60 metros de largura x 1,00 metro de comprimento x 0,20 metros de altura; altura da base para o solo: 0,90 metros; calhas: 0,20 metros de largura x 1,00 metro de comprimento; vidro: 0,90 metros de largura x 1,00 metro de comprimento; inclinação da placa de vidro: $45^{\circ}$. O equipamento utilizado para o desenvolvimento da pesquisa está representado abaixo, na figura 1

. Figura 1 - Destilador solar utilizado na pesquisa para tratamento do lixiviado do aterro sanitário de Sete Lagoas

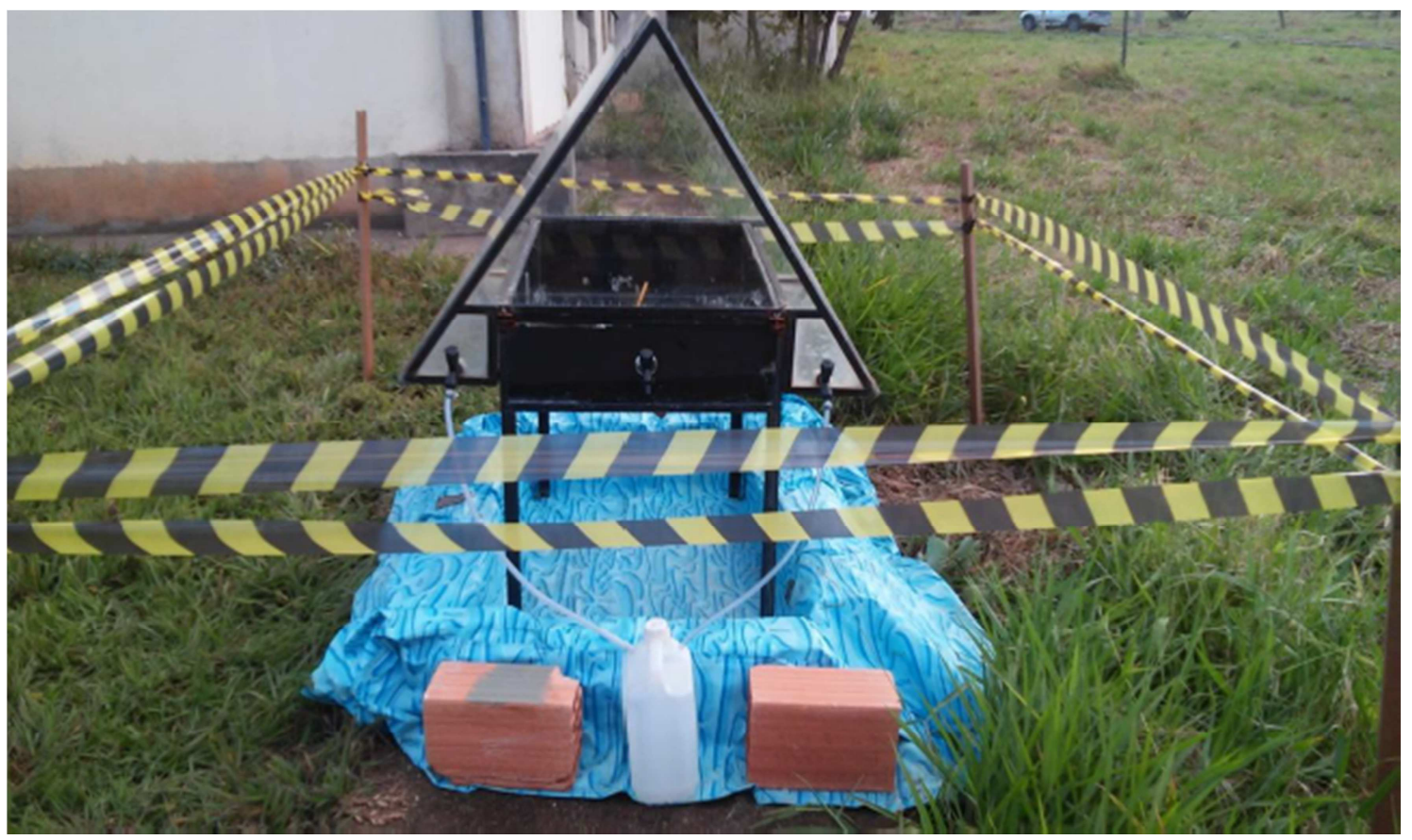

Fonte: A autora, 2015.

O destilador solar foi instalado em um local aberto, com baixo fluxo de pessoas e com significativa exposição à luz solar. O local de instalação foi isolado para garantir a segurança do equipamento. 


\subsection{Coleta do Lixiviado}

O lixiviado utilizado para o desenvolvimento da pesquisa foi produzido no Aterro Sanitário de Sete Lagoas. As amostras foram coletadas no ponto de lançamento do lixiviado na lagoa anaeróbia. Os dados referentes ao lixiviado bruto foram disponibilizados pela Secretaria Municipal do Meio Ambiente de Sete Lagoas.

\subsection{Monitoramento}

O destilador solar, com operação semi-contínua, foi monitorado durante 0 período de junho a outubro de 2015. A operação do equipamento consistiu em aplicar um volume médio inicial de 14,5 L de lixiviado, sendo que o tempo de destilação variou de 19 a 48 dias, em função da radiação solar incidente na região do experimento. Os parâmetros monitorados e a frequência de análise dos mesmos estão indicados na Tabela 1.

Tabela 1 - Parâmetros monitorados durante o desenvolvimento da pesquisa.

\begin{tabular}{llc}
\hline \multicolumn{1}{c}{ Parâmetro } & \multicolumn{1}{c}{ Equipamento } & Frequência \\
\hline $\mathrm{pH}$ & $\mathrm{pH}$ Meter Model - PHS 3B & Diária \\
Condutividade & Condutivímetro Lutron CD - 4303 & Diária \\
Temperatura interna & Termômetro -10 à $110^{\circ} \mathrm{C}$ & Diária \\
DQO & Conforme APHA, et al., 2012 & Periódico \\
Vazão & Proveta de $1000 \mathrm{~mL}$ & Diária \\
\hline
\end{tabular}

A DQO do efluente tratado foi determinada na amostra composta coletada durante o período de destilação do volume médio de 14,5 litros adicionados ao equipamento. Como o tempo de destilação variou de 19 a 48 dias, foi possível obter 33 amostras compostas. A concentração deste parâmetro foi determinada de acordo com o Standard methods for the examination for water and wastwater - 21 th ed. (APHA et al, 2012).

\subsection{Determinação da taxa de aplicação superficial}

A taxa de aplicação superficial representa a quantidade de efluente tratado em volume, por uma unidade de área por dia. Este parâmetro dimensional foi calculado pela razão entre a vazão média de efluente destilado por dia e a área do destilador solar utilizado na pesquisa $\left(0,6 \mathrm{~m}^{2}\right)$. 
3.5 Viabilidade de implantação do destilador em escala real

Para verificar a viabilidade de implantação do processo em escala real, foram avaliados os seguintes itens em comparação à tecnologia de Lagoas (anaeróbia e facultativa), atualmente em operação no aterro Municipal de Sete Lagoas:

- Área - Determinou-se a área do destilador em escala real utilizando a taxa de aplicação superficial mínima encontrada e a vazão máxima de lixiviado produzido no aterro sanitário de Sete Lagoas, durante janeiro a outubro de 2015, e comparou-se a área dimensionada com a área do sistema em operação.

- Eficiência e redução da massa de resíduo - A eficiência do sistema foi determinada baseando na redução da massa de resíduo através da destilação solar.

- Manutenção: A manutenção do processo foi comparada com a do sistema em operação

\section{RESULTADOS E DISCUSSÃO}

\subsection{Monitoramento físico-químico do processo}

A tabela 2 apresenta as características físico-químicas do lixiviado bruto e tratado pelo processo de destilação solar:

Tabela 2 - Características físico-químicas do lixiviado bruto e tratado.

\begin{tabular}{cccc}
\hline Parâmetro & Unidade & Lixiviado Bruto & Lixiviado Tratado \\
\hline Condutividade & $\mu \mathrm{S} / \mathrm{cm}$ & 4140 & 1490 \\
DBO & $\mathrm{mg} / \mathrm{L} \mathrm{O}_{2}$ & 197 & - \\
DQO & $\mathrm{mg} / L ~ O$ & 3934 & 133 \\
DQO/DBO & - & 20 & 97 \\
Remoção de DQO & $\%$ & - & ausente \\
Escherichia coli & $\mathrm{UFC} / 100 \mathrm{~mL}$ & 1100 & 9,0 \\
pH & - & 8,1 & $\mathrm{ND}$ \\
\hline Sólidos Sedimentáveis & $\mathrm{mL} / \mathrm{L}$ & 0,4 & \\
\hline
\end{tabular}

A análise dos dados permite identificar que o lixiviado bruto apresenta elevada concentração de matéria orgânica, predominando o caracter não biodegradável do efluente, em função da alta relação DQO/DBO. Mesmo com esta característica, o processo de tratamento por destilação solar apresenta eficiência de $97 \%$ para remoção de DQO, o que confirma a viabilidade técnica desta tecnologia para esta aplicação. 
Mesmo com a elevada eficiência de remoção de matéria orgânica, ausência de Escherichia coli, visível capacidade de remoção de cor (figura 2), e consequente atendimento aos parâmetros de lançamento definidos na Deliberação Normativa Conjunta COPAM/CERH-MG nº 01, de 05 de maio de 2008 (MINAS GERAIS, 2008), o efluente tratado possui restrições de reuso devido à sua elevada condutividade elétrica, o que faz com que o mesmo tenha características corrosivas, provavelmente em função da concentração de amônia e compostos orgânicos voláteis não removidos no processo.

Figura 2 - Efluente tratado e efluente bruto: variação da cor após o tratamento

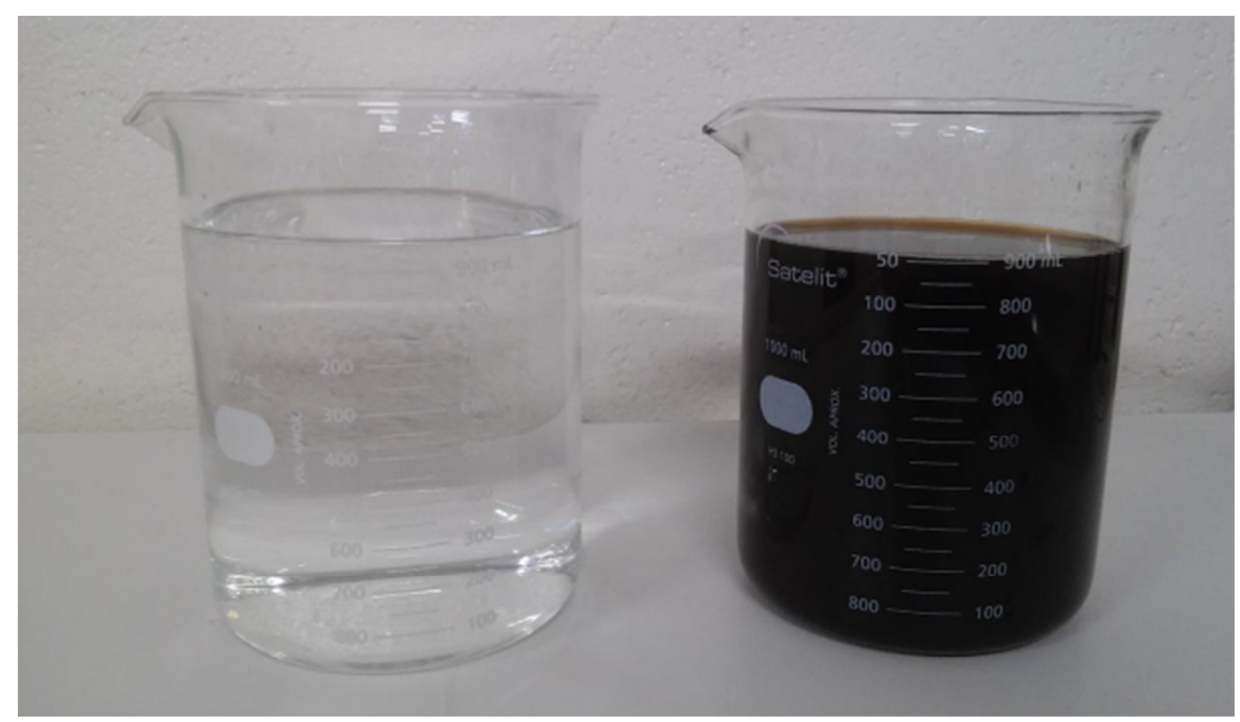

Fonte: A autora, 2015.

\subsection{Taxa de aplicação superficial}

Através da determinação da taxa de aplicação superficial, foi possível estimar a área total requerida para a implantação do destilador solar em escala real para o tratamento do lixiviado do aterro sanitário de Sete Lagoas. A tabela 2 apresenta os resultados obtidos, sendo calculados conforme equação 1 :

$$
I=\frac{V d}{A}
$$

Eq. 1

Onde:

I = Taxa de aplicação superficial;

$\mathrm{Vd}=$ Volume médio de efluente destilado por dia;

$\mathrm{A}=$ Área do destilador. 
Tabela 3 - Taxa de aplicação superficial resultante do volume de lixiviado destilado por dia

\begin{tabular}{cccc}
\hline $\begin{array}{c}\text { Volume Total } \\
\text { destilado }(\mathbf{L})\end{array}$ & $\begin{array}{c}\text { Tempo de } \\
\text { destilação (d) }\end{array}$ & $\begin{array}{c}\text { Vazão de } \\
\text { destilado }(\mathbf{L} / \mathbf{d})\end{array}$ & $\begin{array}{c}\mathbf{I} \\
\left(\mathbf{L} / \mathbf{m}^{\mathbf{2}} \cdot \mathbf{d}\right)\end{array}$ \\
\hline 10,53 & 48 & 0,22 & 0,37 \\
10,33 & 35 & 0,30 & 0,49 \\
11,14 & 21 & 0,53 & 0,88 \\
12,95 & 19 & 0,68 & 1,14 \\
\hline
\end{tabular}

4.3 Viabilidade de Implantação do Destilador em Escala Real

A viabilidade de aplicação em escala real foi definida em função dos seguintes critérios: área de implantação do sistema, eficiência de redução de massa (por consequência geração de sólido) e manutenção do sistema.

- Área

Adotada a taxa de aplicação superficial, pode-se calcular a área do destilador em escala real. Os cálculos foram realizados a partir da equação 2:

$$
A=\frac{Q}{I}
$$

Onde:

$\mathrm{A}=$ Área do destilador em escala real;

Q = Vazão máxima de lixiviado gerado no aterro sanitário de Sete Lagoas por dia;

I = Taxa de aplicação superficial mínima.

$$
\begin{gathered}
A=\frac{2280 \frac{L}{d}}{0,365 \frac{L}{m 2 \cdot d}} \\
A=6246,58 \mathrm{~m} 2
\end{gathered}
$$

O sistema de tratamento de lixiviado atual do aterro sanitário de Sete Lagoas funciona com uma lagoa anaeróbia seguida de uma lagoa facultativa. Este sistema ocupa uma área total de $1.593 \mathrm{~m}^{2}$. Para as condições atuais verificadas neste estudo, a implantação do destilador solar em escala real para o tratamento do lixiviado do aterro sanitário torna-se inviável, uma vez que, a sua instalação demandaria uma área aproximadamente 3,9 vezes maior do que a área do sistema atual de tratamento. 
- $\quad$ Eficiência

O processo de destilação solar além de possibilitar o tratamento do lixiviado, possibilitou também a sua redução, em termos de massa, em aproximadamente $99 \%$. $\mathrm{Na}$ tabela 3 são apresentados os valores obtidos no estudo relacionando a quantidade de massa que entra no destilador com a sua massa de saída, relaciona também o percentual de eficiência do sistema em termos de redução.

Tabela 4 - Relação do volume de lixiviado bruto e tratado com a massa seca do processo de destilação

\begin{tabular}{cccc}
\hline $\begin{array}{c}\text { Lixiviado bruto } \\
(\mathbf{L})\end{array}$ & $\begin{array}{c}\text { Efluente } \\
\text { Tratado }(\mathbf{L})\end{array}$ & $\begin{array}{c}\text { Massa seca } \\
(\mathbf{g})\end{array}$ & $\begin{array}{c}\text { Eficiência de redução } \\
\text { de massa (\%) }\end{array}$ \\
\hline 14,16 & 10,25 & 138,00 & 99,03 \\
14,70 & 10,33 & 156,22 & 98,94 \\
14,44 & 11,14 & 149,53 & 98,96 \\
14,44 & 12,95 & 147,22 & 98,98 \\
\hline
\end{tabular}

Fonte: Dados da pesquisa.

- $\quad$ Manutenção

O destilador solar é um equipamento de fácil manutenção e operação, necessitando apenas de remoção periódica (mensal) do resíduo concentrado que sobra do processo de destilação. No sistema de lagoas, esta manutenção também é necessária, sendo aplicada em uma menor periodicidade (a cada vinte anos) o que exige uma operação mais trabalhosa.

Logo, com a aplicação da tecnologia de destilação por energia solar, não haverá aumento significativo da mão de obra para a manutenção do sistema em relação ao sistema atualmente em operação, tendo ainda, maior controle operacional do equipamento, o que garante a eficiência do processo.

\section{CONCLUSÃO/RECOMENDAÇÃO}

O processo de destilação solar apresentou-se como uma alternativa tecnicamente viável para o tratamento do lixiviado do aterro sanitário de Sete Lagoas, obtendo um efluente tratado em acordo com os parâmetros de lançamento definidos na Deliberação 
Normativa Conjunta COPAM/CERH-MG nº 01, de 05 de maio de 2008 (MINAS GERAIS, 2008).

A tecnologia possui alta eficiência de remoção de DQO (97\%), possibilitando ainda possibilitando a redução significativa da massa de resíduo que entra no destilador, valores da ordem de aproximadamente $99 \%$ de remoção.

Verificou-se também que a instalação de um equipamento de destilação solar, tendo como referência o protótipo usado na pesquisa, não é uma alternativa economicamente viável para ser implantada no aterro sanitário de Sete Lagoas para o tratamento do lixiviado. Para que a implantação deste sistema fosse economicamente viável, o destilador solar deveria apresentar uma taxa de aplicação superficial mínima de $0,860 \mathrm{~L} / \mathrm{m}^{2}$.dia, requerendo desta forma a mesma área para implantação da tecnologia quando comparada ao sistema atualmente aplicado no tratamento do lixiviado.

Desta forma é sugerido, em estudos posteriores, melhorias no equipamento com o fim de promover o aumento no rendimento do processo, podendo ainda melhorar a eficiência de remoção da condutividade visando o reaproveitamento do efluente tratado nas atividades operacionais e de irrigação na unidade de tratamento de resíduos sólidos.

\section{REFERÊNCIAS BIBLIOGRÁFICAS}

BACELAR, H. A. da, M. Tratamento de lixiviados produzidos em aterro de resíduos sólidos urbanos por meio de evaporação forçada. 2010. 76 p. Dissertação (Mestrado em Engenharia Civil) - Universidade Federal do Rio de Janeiro. Rio de Janeiro, dez. 2010 .

BASTOS, F. A. Estudo da remoção de Nitrogênio Amoniacal por processo de arraste com ar (air stripping) em lixiviado de Aterro Sanitário. 2001, p. 165. (Dissertação em Engenharia Ambiental) - Universidade Federal do Espírito Santo. Vitória, 2011.

GIORDANO, G.; BARBOSA FILHO, O.; CARVALHO, R. J. Processos físicoquímicos para tratamento do chorume de aterros de resíduos sólidos urbanos. 2011. 169 p. Coletânea em saneamento ambiental. $1^{\text {a }}$ ed. Rio de Janeiro. Vol. 4.

JUCÁ, J. F. T. et al. Tratamento de lixiviado por evaporação. In: GOMES, L. P. (ORG). Estudos de caracterização e tratabilidade de lixiviados de aterros sanitários para as condições brasileiras. Projeto PROSAB - edital 5. Rio de Janeiro ABES, 360 p. 2009. 
SETE LAGOAS. Prefeitura Municipal. Secretaria de Meio Ambiente e Sustentabilidade. Intranet. Disponível em: < https://pmsl.setelagoas.mg.gov.br/18utilidade-publica/39-coleta-de-lixo>. Acesso em: 25 mai. 2017.

SÁ, L. F. Evaporação natural do lixiviado do aterro da Muribeca através de um destilador solar. 2008. 116 p. (Mestrado em Engenharia Civil) - Universidade Federal de Pernambuco. Recife - Pernambuco. Abril de 2008.

SOUZA, G.; Monitoramento de parâmetros qualitativos e quantitativos de líquidos percolados de aterros sanitários - estudo em piloto experimental. 2005. 85 p. (Mestrado em Engenharia Ambiental) - Universidade Federal de Santa Catarina, Florianópolis - SC. 2005.

SOUSA, M. A. S. B. Estudo da viabilidade da destilação solar para polimento de águas produzidas de petróleo.2010. 133 p. (Doutorado em Engenharia Química) - Universidade Federal do Rio Grande do Norte, Natal, 2010. 